\title{
Achieving Target Pressures with Combined Surgery: Primary Patchless Ahmed Valve Combined with Phacoemulsification vs Primary Phacotrabeculectomy
}

\author{
${ }^{1}$ Oscar Albis-Donado, ${ }^{2}$ Carmen C Sánchez-Noguera, ${ }^{3}$ Lorena Cárdenas-Gómez, ${ }^{4}$ Rafael Castañeda-Diez,
}

${ }^{5}$ Ravi Thomas, ${ }^{6}$ Félix Gil-Carrasco

\begin{abstract}
Purpose: To evaluate the ability of phacoemulsification combined with either primary trabeculectomy (PT) or primary Ahmed glaucoma valve implantation (PAVI) to achieve target intraocular pressures (TIOP) in adults with primary open angle glaucoma.

Materials and methods: Chart review of 214 adult patients operated between January 2002 and June 2008 with a minimum follow-up of 6 months. Group 1 comprised 181 eyes of 166 patients undergoing PT while group 2 included 50 eyes of 49 patients in combination with primary AVI. Target IOPs were pre-determined for each patient and success was defined as an IOP at or lower than target with or without medications. An IOP above target, loss of light perception or need for additional procedures to lower IOP were considered a failure.
\end{abstract}

Results: Mean preoperative IOP was $17.2 \mathrm{~mm} \mathrm{Hg}$ in group 1 and 17.3 in group 2. Mean postoperative IOPs were 10.2 and 9.2 on day $1,12.2$ and 11.6 at year 1 , and 10.7 in both groups at year 5 . Survival rates in groups 1 and 2 were 96.7 vs $96 \%$ at 6 months, 89 vs $96 \%$ at 12 months, 83.5 vs $96 \%$ at 24 months and 79.4 vs $89.1 \%$ at 36,48 and 72 months. Transient bleb leaks were more frequent in group 1 ( 26 eyes, 14.4 vs $0 \%, p=0.001$ ) and transient choroidal detachments were more frequent in group 2 ( 7 eyes, 3.9 vs 6 eyes, 12\%, $p=0.038$ ).

Conclusion: Midterm results for achieving target pressures using combined phacoemulsification with either PT or PAVI are comparable. The profile of complications is different for the two procedures.

Keywords: Phacoemulsification, Cataract, Glaucoma, Ahmed valve, Trabeculectomy, Combined surgery, Target pressure.

How to cite this article: Albis-Donado O, Sánchez-Noguera CC, Cárdenas-Gómez L, Castañeda-Diez R, Thomas R, Gil-Carrasco F. Achieving Target Pressures with Combined Surgery: Primary Patchless Ahmed Valve Combined with

${ }^{1}$ Department of Glaucoma, Mexican Institute of Ophthalmology Queretaro, Mexico

2-4,6 Department of Glaucoma, Association for the Prevention of Blindness, Coyoacan, Mexico

${ }^{5}$ Department of Glaucoma, Cataract, Clinical Epidemiology Queensland Eye Institute, Melbourne, Australia

Corresponding Author: Oscar Albis-Donado, Department of Glaucoma, Instituto Mexicano de Oftalmologia, Circuito Exterior Estadio Corregidora S/N, Col. Colinas del Cimatario CP 76099 Querétaro, Qro México, Phone: 52-4422290776, e-mail: oalbis@ msn.com
Phacoemulsification vs Primary Phacotrabeculectomy. J Curr Glaucoma Pract 2015;9(1):6-11.

\section{Source of support: Nil}

Conflict of interest: None

\section{INTRODUCTION}

Combining glaucoma and cataract surgery for coexistent open angle glaucoma (OAG) and visually significant cataract provides an opportunity for timely visual rehabilitation as well as control of intraocular pressure (IOP) ${ }^{1-3}$

Noben et al and others ${ }^{4,5}$ compared combined phacoemulsification and trabeculectomy (PT) vs trabeculectomy alone as a primary procedure, and reported a better 1-year IOP reduction with trabeculectomy alone. Two systematic reviews by Jampel and Friedman et al found that combined surgeries were better than cataract surgery alone for IOP control and that using phacoemulsification rather than nuclear expression resulted in better IOP control. ${ }^{6,7}$

Implantation of glaucoma drainage devices (GDDs), usually reserved for cases with failed conventional procedures or conditions like neovascular glaucoma and uveitis that are predisposed to failure with standard filtering surgery, are increasingly being considered earlier in the course of the disease. ${ }^{8-11}$ The few published studies on combined cataract and GDDs report encouraging results despite inclusion of refractory glaucomas in the series. ${ }^{12,13}$

Target IOPs are rarely reported as an endpoint for surgical glaucoma trials, ${ }^{14}$ but since they are defined as the IOP level or range at which no further glaucoma damage occurs, ${ }^{15}$ it makes sense to try to report them as a goal for glaucoma surgeries.

Motivated by encouraging results with implants in pseudophakic and aphakic eyes, surgeons at the Asociación Para Evitar la Ceguera en México (Association for the Prevention of Blindness in México) have combined primary Ahmed glaucoma valves with cataract surgery since $2000 .{ }^{16}$ We also perform primary phacotrabeculectomy for such cases and both procedures are taught to residents. This provided an opportunity to compare achievement of target IOP control in cases undergoing PT or PAVI as a primary procedure in a routine situation. 


\section{MATERIALS AND METHODS}

Charts of the 214 patients over 18 years of age operated at the 'Asociación Para Evitar la Ceguera en México' with either phacotrabeculectomy (group 1) or Phaco and Ahmed glaucoma valve (group 2) between January 2002 and June 2008 were reviewed. Each patient had signed a standard consent form and the study was approved by our institution's Ethics Committee for retrospective analysis.

Adult, Mexican Mestizos with primary, pseudoexfoliation or pigmentary open-angle glaucomas not reaching target IOP and in need of cataract surgery were included. Inclusion required a minimum of 6 months post-surgical follow-up. Patients with other types of glaucoma, retinal disease, nystagmus, previous conjunctival, retinal, refractive or other corneal surgeries were excluded.

Surgery was performed by both faculty and fellows. There were no specific instructions or criteria to decide between the two procedures; the choice was left to the consultant surgeon. While the type of procedure used was decided by the surgeon, in our department valves were generally preferred in moderate and severe cases, and/or when it was felt a trabeculectomy had a higher risk of failure, higher chance of infection for any reason (e.g. manual labor in the fields) and in patients judged unlikely to comply with follow-up visits.

Phacotrabeculectomy was initiated with the initial steps of trabeculectomy. The choice of limbus vs fornixbased conjunctival flap and single $v$ s twin site was made by the surgeon. For twin site surgery, following construction of the scleral flap, a separate corneal incision was made for the phacoemulsification. Once the IOL was implanted, viscoelastic was left in the anterior chamber, the trabeculectomy was completed and a peripheral iridectomy was performed. Viscoelastic was removed and closure of the scleral flap was titrated to allow ooze of aqueous either spontaneously or on gentle pressure. Conjunctiva was closed using 10-0 nylon, a continuous running suture was used for limbus-based trabeculectomies and episcleral mattress plus running sutures as needed were used for fornix-based trabeculectomies.

The use of mitomycin for phaco trab is not routine in the department and all such operations were done without mitomycin. The decision and timing of suture lysis was made by the surgeon.

The AGV S2 model (New World Medical, California, US) was used for all PAVI procedures. The surgical technique used in these cases has been described in detail elsewhere and does not involve use of a scleral patch graft. ${ }^{17-19}$ In brief, a fornix-based conjunctival flap was created in the superotemporal quadrant and the Ahmed plate was sutured to the scleral bed 8 to
$10 \mathrm{~mm}$ behind the limbus with 7-0 silk. A scleral tunnel initiated 3 to $4 \mathrm{~mm}$ from the limbus was constructed using a $23 \mathrm{G}$ needle, bent in a ' $\mathrm{Z}$ ' formation to avoid interference from the eyelids, brow or lid speculum. ${ }^{20}$ The direction of the needle was abruptly changed at the limbus to make the anterior chamber entry parallel to the iris. The needle was mounted on a viscoelastic syringe, so the anterior chamber could be reformed after needle entry into the anterior chamber. The AGV silicone tube was then trimmed to create a 30 to $45^{\circ}$ bevel and inserted through the tunnel into the anterior chamber. Phacoemulsification was then performed, according to surgeon's preference. The conjunctiva was closed using the same 7-0 silk. The postoperative regimen in both the groups included prednisolone acetate $1 \%$ every 2 hours during the daytime in the first month and tapered slowly over 3 months. Antibiotic drops (ciprofloxacine, moxifloxacine or gatifloxacine) four times a day were used for 2 weeks, along with a cycloplegic agent for the first month in all patients.

Postoperatively, patients were examined at days 1, 3, $7,14,30$ and months $2,3,6,12$, and at least once a year thereafter.

Target IOPs were determined for each patient depending on the mean deviation of the last visual fields before surgery. Based on the mean deviation, the eyes were arbitrarily divided into three groups: $-5.99 \mathrm{~dB}$ or better (mild glaucomas), between -6 and $-11.99 \mathrm{~dB}$ (moderate glaucomas) and those with MD worse than $-12 \mathrm{~dB}$ (severe glaucomas) and had their target IOPs set at 16, 14 and 12 $\mathrm{mm} \mathrm{Hg}$ respectively.

Success was defined as an IOP at or lower than target with or without medications. Inability to achieve target IOP with medications, loss of light perception and/or need for additional procedures to lower IOP was considered a failure.

Visual acuity was measured by a technician using Snellen charts, and best-corrected visual acuity was recorded. Slit-lamp examination was performed and IOPs measured using Goldmann applanation tonometry between 8 am and 1 pm by the surgeon, a fellow or a resident. Fields were performed as per our clinical routine. Each active ingredient of single or combined drops or oral formulations was counted as a separate medication.

Statistical analysis was performed using SPSS version 19. Means for continuous variables were compared among the different groups using analysis of variance (ANOVA). Associations between categorical variables were studied with Chi-square test; Fisher's exact test was used when fewer than 5 cases were present at a given category. Relative risk and confidence intervals were calculated for these data. Multivariate models were constructed to 
determine the effect of risk factors on the final survival rate. As both the eyes of 16 patients were included in the analysis, generalized estimating equations were used for multivariate analysis of risk factors for failure, adjusting for dependencies when both eyes of the same patient had been operated, repeated measures and missing data. Forward stepwise selection of covariates and factors significant in the simple analysis was used for the final multivariate model. Survival analysis was performed using the Kaplan-Meier life-Table method, using the logrank test for comparing survival times between groups.

\section{RESULTS}

Group 1 comprised 181 eyes of 166 patients while group 2 consisted of 50 eyes of 49 patients; $68 \%$ were female. Mean age was 69.1 years for group 1 and 72.8 for group 2; this was statistically different but did not affect results in either uni or multivariable analysis (Table 1).

One hundred and forty two eyes had severe glaucoma (61.7\%), 55 had moderate glaucoma (23.9\%) and 33 had mild glaucoma (14.3\%). Mean preoperative IOP was $17.2 \mathrm{~mm} \mathrm{Hg}$ in group 1 and 17.3 in group 2. Mean target IOP for all eyes was $13.05 \mathrm{~mm} \mathrm{Hg}$. The IOP was lowered to 10.2 and 9.2 by day $1,12.2$ and 11.6 by year 1 , and 10.7 and 10.7 by year 5 . Differences were not statistically significant at any time-point (Graph 1). Mean last recorded IOP was statistically lower for group 2 (12.2 vs 11.1, $\mathrm{p}=0.025$, 95\% Ci 0.14 to 2.13 ).

Survival rates for maintaining target IOP in groups 1 vs 2 eyes were 96.7 vs $96 \%$ at 6 months, 89 vs $96 \%$ at 12 months, 83.5 vs $96 \%$ at 24 months and 79.4 vs $89.1 \%$ at 36, 48 and 72 months, the differences were not significant and confidence intervals for the difference ranged from -0.35 to $0.51 \%$ at each time-point. After 36 months of follow-up, the number of eyes remaining was less than half of the original cohort, so most of our comments will be limited to within that time period.

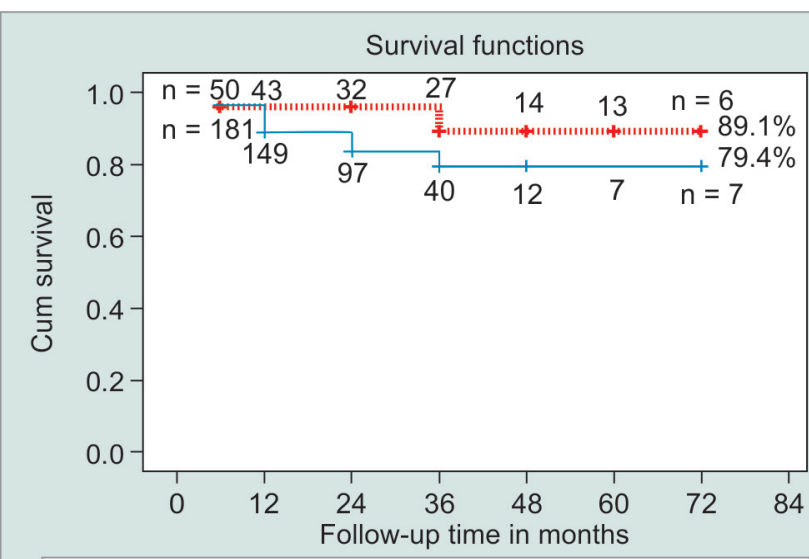

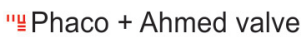

$\sim$ Phaco + trabeculectomy

Graph 2: Kaplan-Meier survival curve for phaco-Ahmed vs phacotrabeculectomy, the difference between the 2 groups is not statistically significant. Numbers in boxes represent the number of eyes still under observation at the corresponding follow-up time

Table 1: Demographic data by group

\begin{tabular}{|c|c|c|c|}
\hline Characteristic & $\begin{array}{l}\text { Phaco-trab } \\
(n=181)\end{array}$ & $\begin{array}{l}\text { Phaco-AVI } \\
(n=50)\end{array}$ & $p$ \\
\hline $\begin{array}{l}\text { Age, year } \\
(\text { mean } \pm S D)\end{array}$ & $69.2 \pm 8.8$ & $72.8 \pm 8.3$ & 0.010 \\
\hline Gender, female, N (\%) & $122(67.4 \%)$ & $35(70 \%)$ & 0.434 \\
\hline Eye OD, N (\%) & $97(53.6 \%)$ & $20(40 \%)$ & 0.061 \\
\hline $\begin{array}{l}\text { Follow-up months } \\
\text { (mean } \pm \text { SD) }\end{array}$ & $22.1 \pm 15.3$ & $34.4 \pm 23$ & $<0.001$ \\
\hline $\begin{array}{l}\text { Preoperative IOP } \\
\mathrm{mm} \text { Hg (mean } \pm \text { SD) }\end{array}$ & $17.3 \pm 5.5$ & $17.3 \pm 4.5$ & 0.943 \\
\hline $\begin{array}{l}\text { Target IOP mm Hg } \\
(\text { mean } \pm \text { SD) }\end{array}$ & $13.1 \pm 1.5$ & $12.8 \pm 1.3$ & 0.249 \\
\hline $\begin{array}{l}\text { Preoperative visual } \\
\text { field damage severity } \\
(\mathrm{N}, \%)\end{array}$ & & & 0.417 \\
\hline - Mild & $30(16.6 \%)$ & $4(8 \%)$ & \\
\hline - Moderate & $42(23.2 \%)$ & $13(26 \%)$ & \\
\hline - Severe & $109(60.2 \%)$ & $33(66 \%)$ & \\
\hline
\end{tabular}

Mean survival time (as determined by target IOP) for PT was 61.1 months (95\% CI 57.17-65.01); for PAVI this was 66.9 months (95\% CI 62.12-71.66); the difference was not statistically significant (Graph 2).

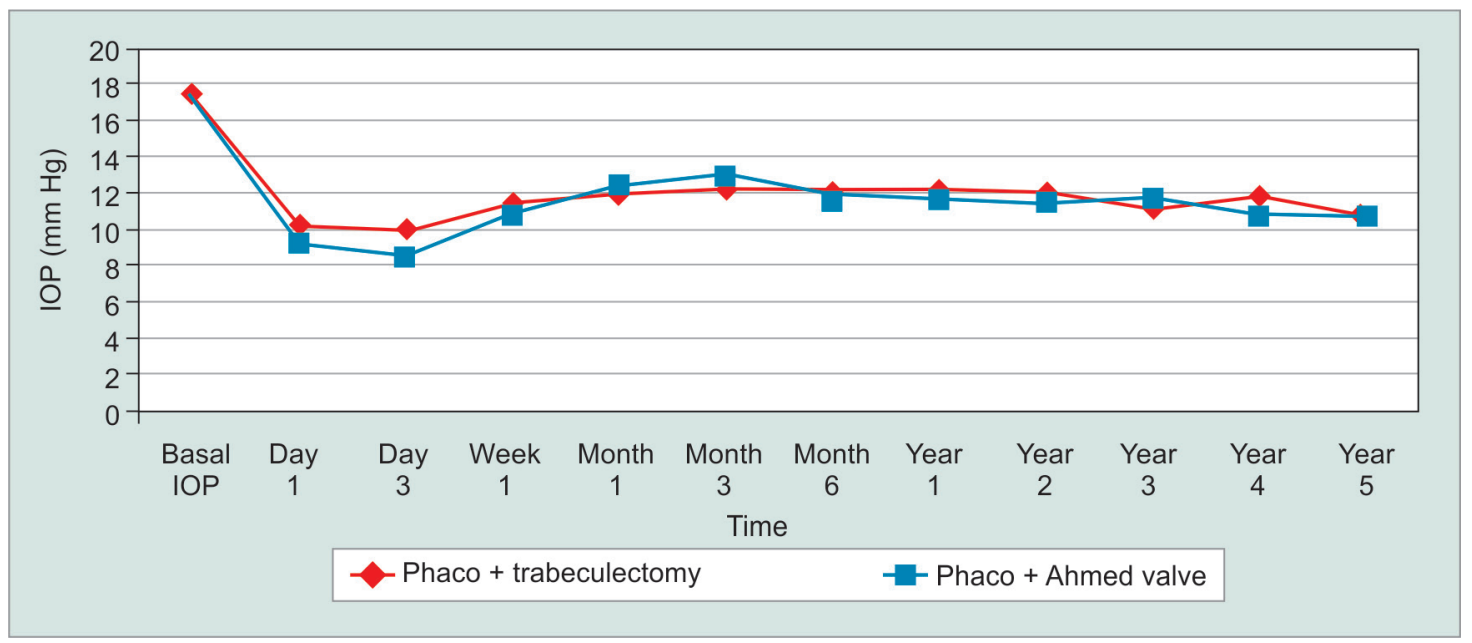

Graph 1: Mean IOP according to technique during follow-up. IOP was similar at all time-points 
Table 2: Number of eyes reaching their corresponding target IOP without medications in each group, and mean number of medications needed in each group at last follow-up. None of the differences were statistically significant

\begin{tabular}{|c|c|c|c|c|c|}
\hline & \multicolumn{3}{|c|}{ Target IOP with no medications } & \multirow{2}{*}{$\begin{array}{l}\text { Total eyes reaching } \\
\text { target with no } \\
\text { medications }\end{array}$} & \multirow{2}{*}{$\begin{array}{l}\text { Mean number of } \\
\text { medications }\end{array}$} \\
\hline & 12 & 14 & 16 & & \\
\hline Phaco-trab & $\begin{array}{l}27(24.8 \% \text { of } \\
109 \text { eyes) }\end{array}$ & $\begin{array}{l}11(26.2 \% \text { of } \\
42 \text { eyes) }\end{array}$ & $\begin{array}{l}5(17.2 \% \text { of } \\
29 \text { eyes })\end{array}$ & $\begin{array}{l}43(23.9 \% \text { of } \\
180 \text { eyes })\end{array}$ & 1.60 \\
\hline Phaco AVI & $\begin{array}{l}8(24.2 \% \text { of } \\
33 \text { eyes })\end{array}$ & $\begin{array}{l}3(23.1 \% \text { of } \\
13 \text { eyes }\end{array}$ & $\begin{array}{l}1(25 \% \text { of } 4 \\
\text { eyes })\end{array}$ & $12(24 \%$ of 50 eyes) & 1.58 \\
\hline $\begin{array}{l}\text { Mean number of } \\
\text { medications }\end{array}$ & 1.69 & 1.45 & 1.45 & & \\
\hline
\end{tabular}

Table 3: Summary of postoperative complications by surgical technique (CRVO: central retinal vein occlusion)

\begin{tabular}{llll}
\hline Complications & $\begin{array}{l}\text { Phaco-trab } \\
(n=181)\end{array}$ & $\begin{array}{l}\text { Phaco-AVI } \\
(n=50)\end{array}$ & $p$ \\
\hline Transient choroidal detachment $(\mathrm{N}, \%)$ & $7(3.9 \%)$ & $6(12 \%)$ & 0.038 \\
Bleb leak (N, \%) & $26(14.4 \%)$ & 0 & $<0.001$ \\
Transient corneal edema $(\mathrm{N}, \%)$ & $22(12.2 \%)$ & $2(4 \%)$ & 0.071 \\
Transient flat anterior chamber (N, \%) & $1(0.6 \%)$ & 0 & 0.784 \\
CRVO (N, \%) & $1(0.6 \%)$ & 0 & 0.784 \\
& 0 & 0 & \\
& 0 & 0 & \\
Tube extrusion/exposure $(\mathrm{N}, \%)$ & 0 & 0 & \\
Diplopia (N, \%) & $\mathrm{NA}$ & 0 & \\
\hline NA: Not available & 0 & 0 &
\end{tabular}

The number of medications needed to control IOP during the full follow-up period were similar at all timepoints except month 6 (0.92 in group 1 vs 0.58 in group 2 $(\mathrm{p}=0.023)$, and month 12 (1.41 in group 1 vs 0.83 in group $2(\mathrm{p}=0.002)$. The number of eyes reaching target without medications and the mean number of medications used in each target group are shown in Table 2.

Thirty-three of 181 eyes (18.23\%) in group 1 underwent suturelysis and $44(24.31 \%)$ required needling with 5 -fluorouracil as decided by the surgeon. These two variables had no effect on the final success status or the number of bleb leaks. Eyes in group 2 did not receive similar interventions.

As shown in Table 3, transient bleb leaks were more frequent in group 1 (26 eyes, $14.4 \%$ vs $0 \%$ ) and transient choroidal detachments were more frequent in group 2 (7 eyes, $3.9 \%$ in group 1 vs 6 eyes, $12 \%$ in group $2, p=0.038)$

\section{DISCUSSION}

The generally accepted initial approach for OAG patients in need of filtering surgery is trabeculectomy. Different techniques of combined surgeries have been described to control IOP and deal with any clinically significant cataract that may be present. ${ }^{21}$ Surgical times and complications vary widely depending on surgeon experience, technology available and precautions taken during the procedure.

Using target IOP as an endpoint should have the potential to better predict if any kind of surgery can better achieve our ultimate goal, to prevent further glaucoma damage. ${ }^{15}$ A swift comparison of visual field progression of the CIGTS patients, which used target IOP as the therapeutic target ( $37 \%$ mean IOP reduction), ${ }^{22}$ and the EMGT patients $(25 \% \text { mean IOP reduction })^{23}$ shows a large difference in progression $(21.3 \%$ surgery and $25.5 \%$ medicine over 8 years $v s 59 \%$ over 8 years). Target IOPs are also a much stricter outcome than the usual $21 \mathrm{~mm} \mathrm{Hg}$ cut off or even the more recently advocated thresholds of 18 or $15 \mathrm{~mm} \mathrm{Hg}{ }^{24-28}$

The IOP reduction achieved using phacoemulsification combined with Ahmed valve glaucoma implants was comparable to that obtained using phacoemulsification with trabeculectomy. As far as IOP lowering medications are concerned the results tend to favor the AGV option but are unlikely to be clinically significant. While the numbers are small (and statistically not significant) the Kaplan-Meier curves suggest AGV has potentially longer survival. The number needed to treat (NNT) is 10 (CI $95 \%-27$ to 5, equivalent to an absolute risk reduction (ARR) ranging from -0.036 to 0.185 ). If we consider the absolute success and failure rates, without taking time into account, the NNT is 16 (CI 95\% - 19 to 7, equivalent to ARR -0.053 to 0.140 ). And while we did find a significant difference in last recorded IOP between the groups, the magnitude of this divergence is small and does not take into account the differential follow-up times.

Phacotrabs are generally performed using MMC modulation. REF, However, we did not use MMC and 
it is possible that such supplementation of phacotrabeculectomy and/or the use of post operative 5 fluorouracil in all eyes might have resulted in better IOP control in this group. The IOP levels and number of early bleb-leaks in this group are comparable to previous reports. ${ }^{29-31} \mathrm{On}$ the other hand late onset bleb-leaks, more commonly seen with the use of antifibrotic agents and a known risk factor for bleb-related infections, ${ }^{32}$ were not found in our series. ${ }^{33}$

Since the risk of early bleb leaks is higher with trabeculectomies ${ }^{29}$ and in our series with phacotrabeculectomies, the need for closer monitoring may justify a tube when the patient lives far or will have poor compliance with follow-up visits. ${ }^{34}$

Other complications seem to have a lower incidence than what is published; two deserve special attention. The lack of cases with hyphema is probably related to the retrospective nature of the present study obtaining data via a chart review. Small hyphemas were probably not mentioned in the chart. On the other hand, the lack of tube extrusions and exposures is actually closer to truth, since any such complication would need a surgical procedure that would necessarily be recorded at the chart; our patchless technique has been reported to have a low rate of tube extrusions/exposure. ${ }^{19,35}$

Since this was a retrospective study, it was not possible to objectively monitor the precise time each procedure took. In our hands Ahmed valves using the patchless technique can be implanted in 30 to 40 minutes for residents in their first surgeries to 10 to 15 minutes for attending surgeons. Once implanted, a postoperative IOP course is reasonably predictable and permits the patient to return to their normal activities earlier than a trabeculectomy. Also an eye with an Ahmed valve can more easily resist trauma, is less prone to infections, has less issues with swimming or contact lenses, and has similar induction of astigmatism. ${ }^{36}$

This report suffers from the limitations of a chart review and the loss to follow-up. It also reflects practice in a teaching hospital with both consultants and fellows with differing skill levels performing surgery.

To replace a standard technique, the new procedure should have better results, fewer complications or should be cheaper. Our uncontrolled preliminary results with an NNT of 10 suggest that combined Ahmed valve and phacoemulsification can be a potential alternative for eyes with OAG needing primary filtering surgery plus cataract removal. The AGV does add to the price of surgery and it remains to be seen if long-term results will support the potential advantages of shorter time, less postoperative monitoring and the cost benefit ratio.

\section{REFERENCES}

1. Lonstaff S, Wornald RP, Mazover A, Hitchings RA. Glaucoma triple procedures: efficacy of intraocular pressure control and visual outcome. Ophthalmic Surg 1990 Nov;21(11):786-793.

2. Nielsen PJ. Combined Small-incision cataract surgery and trabeculectomy: a prospective study with 1 year of follow-up. Ophthalmic Surg Lasers 1997 Jan;28(1):21-29.

3. Wedrich A, Menapace R, Radax U, Papapanos P. Long-term results of combined trabeculectomy and small incision cataract surgery. J Cataract Refract Surg 1995 Jan;21(1):49-54.

4. Noben KJ, Linsen MC, Zeyen TG. Is combined phacoemulsification and trabeculectomy as effective as trabeculectomy alone? Bull Soc Belge Ophthalmol 1998;270:85-90.

5. Lochhead J, Casson RJ, Salmon JF. Long-term effect on intraocular pressure of phacotrabeculectomy compared to trabeculectomy. Br J Ophthalmol 2003 Jul;87(7):850-852.

6. Friedman DS, Jampel HD, Lubomski LH, Kempen JH, Quigley H, Congdon N, Levkovitch-Verbin H, Robinson KA, Bass EB. Surgical strategies for coexisting glaucoma and cataract: an evidence-based update. Ophthalmology 2002 Oct;109(10):1902-1913.

7. Jampel HD, Friedman DS, Lubomski LH, Kempen JH, Quigley H, Congdon N, Levkovitch-Verbin H, Robinson KA, Bass EB. Effect of technique on intraocular pressure after combined cataract and glaucoma surgery: an evidence-based review. Ophthalmology 2002 Dec;109(12):2215-2224.

8. Gedde SJ, Schiffman JC, Feuer WJ, Herndon LW, Brandt JD, Budenz DL. Treatment outcomes in the tube versus trabeculectomy study after one year of follow-up. Am J Ophthalmol 2007 Jan;143(1):9-22.

9. Gedde SJ, Schiffman JC, Feuer WJ, Herndon LW, Brandt JD, Budenz DL. Three-year follow-up of the tube versus trabeculectomy study. Am J Ophthalmol 2009 Nov;148(5): 670-684.

10. Wilson MR, Mendis U, Smith SD, Paliwal A. Ahmed glaucoma valve implant vs trabeculectomy in the surgical treatment of glaucoma: a randomized clinical trial. Am J Ophthalmol 2000 Sep;130(3):267-273.

11. Wilson MR, Mendis U, Paliwal A, Haynatzka V. Longterm follow-up of primary glaucoma surgery with Ahmed glaucoma valve implant versus trabeculectomy. Am J Ophthalmol 2003 Sep;136(3):464-470.

12. Molteno AC, Whittaker KW, Bevin TH, Herbison P. Otago glaucoma surgery outcome study: long-term results of cataract extraction combined with Molteno implant insertion or trabeculectomy in primary glaucoma. Br J Ophthalmol 2004 Jan;88(1):32-35.

13. Chung A, Aung T, Wang JC, Chew PT. Surgical outcomes of combined phacoemulsification and glaucoma drainage implant surgery for Asian patients with refractory glaucoma with cataract. Am J Ophthalmol 2004 Feb;137(2):294-300.

14. Musch DC, Gillespie BW, Lichter PR, Niziol LM, Janz NK. CIGTS study investigators. Visual field progression in the collaborative initial glaucoma treatment study the impact of treatment and other baseline factors. Ophthalmology 2009 Feb; 116(2):200-207.

15. American Academy of Ophthalmology. Primary openangle glaucoma, preferred practice pattern [Internet]. San Francisco: American Academy of Ophthalmology, 2010. Available at: http://one.aao.org/ce/practiceguidelines/ppp_ content. aspx?cid=93019a87-4649-4130-8f94-b6a9b19144d2. [Accessed December 29, 2012]. 
16. Gil Carrasco F, Paczka JA, Jiménez Román J, Gilbert Lucido ME, De los Ríos D, Sánchez Castellanos VE. Experiencia clínica inicial con la válvula de Ahmed: reporte de 278 casos con glaucoma incontrolable. St Ophthalmol 1997;16:117-122.

17. Ah-Chan JJ, Molteno AC, Bevin TH, Herbison P. Otago glaucoma surgery outcome study: follow-up of young patients who underwent Molteno implant surgery. Ophthalmology 2005 Dec;112(12):2137-2142.

18. Gil-Carrasco F, Salinas-VanOrman E, Recillas-Gispert C, Paczka JA, Gilbert ME, Arellanes-Garcia L. Ahmed valve implant for uncontrolled uveitic glaucoma. Ocul Immunol Inflamm 1998 Mar;6(1):27-37.

19. Albis-Donado O, Gil-Carrasco F, Romero Quijada R, Thomas R. Evaluation of Ahmed glaucoma valve implantation through a needle-generated scleral tunnel in Mexican children with glaucoma. Indian J Ophthalmol 2010 SepOct;58(5):365-373.

20. Albis-Donado, O. The Ahmed Valve. In: Shaarawy T, Mermoud A, editors. Atlas of Glaucoma Surgery. Jaypee Brothers Medical Publishers: New Delhi, India 2006. p. 58-76.

21. Vizzeri G, Weinreb RN. Cataract surgery and glaucoma. Curr Opin Ophthalmol 2010 Jan;21(1):20-24.

22. Musch DC, Gillespie BW, Niziol LM, Lichter PR, Varma R. CIGTS Study Group. Intraocular pressure control and longterm visual field loss in the collaborative initial glaucoma treatment study. Ophthalmology 2011 Sep;118(9):1766-1773.

23. Leske MC, Heijl A, Hyman L, Bengtsson B, Dong L, Yang Z. MGT Group. Predictors of long-term progression in the early manifest glaucoma trial. Ophthalmology 2007 Nov; 114(11):1965-1972.

24. WuDunn D, Cantor LB, Palanca-Capistrano AM, Hoop J, Alvi NP, Finley C, Lakhani V, Burnstein A, Knotts SL. A prospective randomized trial comparing intraoperative 5-fluorouracil vs mitomycin $\mathrm{C}$ in primary trabeculectomy. Am J Ophthalmol 2002 Oct;134(4):521-528.

25. Jampel HD, Solus JF, Tracey PA, Gilbert DL, Loyd TL, Jefferys JL, Quigley HA. Outcomes and bleb-related complications of trabeculectomy. Ophthalmology 2012 Apr;119(4):712-722.

26. Belovay GW, Naqi A, Chan BJ, Rateb M, Ahmed II. Using multiple trabecular micro-bypass stents in cataract patients to treat open-angle glaucoma. J Cataract Refract Surg 2012 Nov;38(11):1911-1917.

27. Cillino S, Di Pace F, Cillino G, Casuccio A. Biodegradable collagen matrix implant vs mitomycin- $\mathrm{C}$ as an adjuvant in trabeculectomy: a 24-month, randomized clinical trial. Eye (Lond) 2011 Dec;25(12):1598-1606.

28. Kiuchi Y, Tsujino C, Nakamura T, Otori Y, Mochizuki H. Phacoemulsification and trabeculotomy combined with goniosynechialysis for uncontrollable chronic angle-closure glaucoma. Ophthalmic Surg Lasers Imaging 2010 MayJun;41(3):348-354.

29. Gedde SJ, Herndon LW, Brandt JD, Budenz DL, Feuer WJ, Schiffman JC. Surgical complications in the tube versus trabeculectomy study during the first year of follow-up. Am J Ophthalmol 2007 Jan;143(1):23-31.

30. Carlson DW, Alward WL, Barad JP, Zimmerman MB, Carney BL. A randomized study of mitomycin augmentation in combined phacoemulsification and trabeculectomy. Ophthalmology 1997 Apr;104(4):719-724.

31. Shin DH, Ren J, Juzych MS, Hughes BA, Kim C, Song MS, Yang KJ, Glover KB. Primary glaucoma triple procedure in patients with primary open-angle glaucoma: the effect of mitomycin $C$ in patients with and without prognostic factors for filtration failure. Am J Ophthalmol 1998 Mar;125(3): 346-352.

32. Soltau JB, Rothman RF, Budenz DL, Greenfield DS, Feuer W, Liebmann JM, Ritch R. Risk factors for glaucoma filtering bleb infections. Arch Ophthalmol 2000 Mar;118(3):338-342.

33. Greenfield DS, Liebmann JM, Jee J, Ritch R. Late-onset bleb leaks after glaucoma filtering surgery. Arch Ophthalmol 1998 Apr;116(4):443-447.

34. Gedde SJ. Results from the tube versus trabeculectomy study. Middle East Afr J Ophthalmol 2009 Jul;16(3):107-111.

35. Gil-Carrasco F, Albis-Donado O, Castañeda-Diez R, TuratiAcosta M, Garcia-Huerta M, Jimenez-Roman J. Long-term results in 912 Ahmed valves without graft patch in Mexico: 16 years of follow-up. 6th International Congress on Glaucoma Surgery, Glasgow, Scotland, UK 2012.

36. Leal Rodriguez R, Albis-Donado O, Gil-Carrasco F. Induced keratometrical change after phacoemulsification cataract surgery combined with trabeculectomy or Ahmed valve. Invest Opthalmol Vis Sci 2010 Apr;51(13):4453. 